\title{
correspondence
}

\section{Integrity in science}

SIR,- - In a leading article in Nature (September 29, 1972) there occurs the following passage relating to my then recently published book, Science at the Crossroads: "Professor Dingle goes on to complain that a promised leading article rounding off the correspondence has never appeared, apparently oblivious of the way in which his promises to 'bring discredit on the journal' may have discouraged the judicious summing-up for which he asked". Although this was misleading, I ignored it because my primary aim, as my book makes clear, was to ensure that respect for moral integrity should take precedence of all other considerations in scientific practice, and I did not wish to add the relatively trivial question of my own reputation to the already excessive number of possibilities that had been exploited to divert attention from that. On the one occasion on which I did defend myself, the reason was that that had become my only means of establishing beyond doubt that the statements in my book were true. I had then, as now, no object but to make known the actual degree of awareness of moral responsibility within the scientific community, with the ultimate aim of raising it.

I hoped that this feature of the situation had thus been finally disposed of. A recent incident now makes it necessary, however, for me to state the facts relating to the passage quoted above. I have a complete record of my correspondence with Nature on this matter, and the only possible basis for what is described as "his [Dingle's] promises to bring discredit on the journal [Nature]" is the following extract from my letter of May 20, 1969 to the then editor: "It is now about nine months since I sent you my reply to Synge : it remains unpublished, and it is becoming increasingly difficult to present Nature's attitude without reflecting discredit on the journal. I repeat that I do not want to do this, but I must get the truth brought out, whatever it involves, and you are leaving me no alternative." There are many other passages in the correspondence in which I strongly urged the editor not to make necessary revelations which would lower the high reputation which Nature had acquired under the editor- ship of Lockyer and Gregory, which I had a strong desire to preserve, reinforced by my long and intimate association with the journal in Gregory's days. The reference to "my reply to Synge" is explained in my book; here it is necessary only to say that what is described as "the judicious summing-up for which he [Dingle] asked" was not asked for by me, but was spontaneously promised by the editor on November 24, 1969 (six months after my alleged "promises" which, it is stated, "may have discouraged" its appearance) as a substitute for my reply to Synge, which I would far rather have had and which might have settled the whole matter there and then (for details see my book). This, like the "judicious summing-up", has never been published.

This incident has implications for the future as well as, and far more important than, those for the past. Those who share my view of the supremacy of moral obligations over considerations of expediency in science can no longer remain unconvinced that the continued evasion or ignoring of the simple question concerning the rates of two clocks in uniform relative motion which $\mathbf{I}$ have asked many times-conspicuously in my book and lastly, so far as Nature is concerned, in my letter there of August 31, 1973 (hereinafter called L) - constitutes a violation of the basic ethical principle of science, with the gravest implications. If evidence of this were still needed, it would be given by the existence of a letter, signed by 12 persons highly qualified in the fields of physics, astronomy, space research, electrical engineering, the Open University, psychiatry, archaeology, religion (three separate branches of the Christian Church of world-wide repute), philosophy, law-who constitute a small fraction of the number who have expressed accordant convictions. This letter asks, in view of the objective facts disclosed in my book, for authoritative reassurance, by the provision of a direct answer to my question, that integrity is still preserved within the scientific community. It has not succeeded in being published in any journal where its appearance would be appropriate and effective. The signatories, many of whom claim no technical qualifications in relativity theory, see clearly that the question asked is perfectly intelligible without technical knowledge, and that the failure to provide an equally intelligible answer is unmistakably a moral failure.

Notwithstanding the obviousness of this to any reader of my book or of $\mathrm{L}$, no comment on $\mathrm{L}$ of any kind has appeared in Nature until Kilmister's recent offer of a solution to the problem in the issue of December 6, 1974. In one of the Three Musketeers stories, General Monk's skill in diplomacy is said to be shown by his practice, when wished "Good morning", of not replying immediately but waiting twelve hours and then saying "Good evening". Kilmister seems to have emulated Monk. In $\mathrm{L}$, in an attempt to prevent repetition of earlier evasions of my question, I repeated that it had nothing to do with, among other things, "coordinate systems or frames of reference". Kilmister waits 15 months and then says (Nature, 252, 439; 1974) "The basis of Dingle's long-standing arguments with the relativists seems to be his insistence on the arbitrary nature of inertial frames." $L$ is, however, still available for reference, and anyone may evaluate Kilmister's judgment by looking it up. He will see that there are only two possible ways of answering my question which are compatible with the ethical demands of science: they are (1) the completion by a single phrase of the following sentence: "The slowerworking of the two clocks, $A$ and $B$, mentioned in the question-which, as shown in L and elsewhere, the theory requires actually, and not merely apparently, to work at different ratesis that which ..."; (2) acknowledgment that the theory permits no means of proving that A works more slowly than $\mathbf{B}$ that is not applicable with equal validity to prove that $B$ works more slowly than $\mathrm{A}$, and that, since this involves a physical impossibility, the theory is untenable.

I think it must now be clear to every reader, whether physicist or not, whose mind has not already been finally closed on this subject, that the basic issue here is a moral one, all intellectual, metaphysical and mathematical considerations being secondary, and that the possibility of continued belief in the moral integrity of the scientific community, the social significance of which in the present age needs no pointing out, depends on the early 
provision, by some body or person generally understood to be qualified to speak with authority on the theory, of one of these answers, unobscured by additional verbiage, diagrams or arrays of symbols of any kind.

\section{Herbert Dingle}

\section{Purley, Surrey}

SiR,-Your readers should first know the circumstances in which this exchange of correspondence is published. Professor Dingle has complained that the leading article of September 29, 1972, was defamatory of him, but has undertaken not to take legal action if you publish a letter (above) which I consider might be damaging of me, your predecessor, without the following explanation, however tedious.

I know of nobody who wishes to damage Dingle or his reputation. I would be sorry, but at the same time exceedingly surprised, if the leading article to which he refers had been read in that sense. It was a forthright article but pallid compared with some of the polemics with which Dingle has entertained the readers of Nature in the past quarter of a century.

On one small point, whose relevance to his complaint is debatable, Dingle is right. His promise to "bring discredit" on Nature was made before and not after I rashly volunteered to write a leading article explaining why his argument is false. I abandoned this project after letters from him such as that of April 6, 1971, in which he wrote that "action on your part even now would make a full exposure of the ethical aspect of the matter unnecessary". It would no doubt have been more courteous to have told him explicitly that, as far as I was concerned, his dealings with Nature were at an end, but the correspondence had become offensive and repugnant. Dingle may not appreciate how the manner in which he has pressed his case has often forfeited him the indulgence that one of his age and wit would ordinarily command.

Your readers should know that the 'recent incident' referred to in Dingle's letter was my comment to the editor of an overseas journal that the author of an article submitted for publication and purporting to be an objective account of this business had at no time sought to obtain my side of the story.

Dingle is wrong to claim that this is an ethical issue. His view that special relativity is a house of cards has been widely aired and amply refuted. I note that he does not refer to the simple statement of the reasons why he is mistaken presented in the leading article of which he now complains.

Dingle's error is primitive, as can be told from his penultimate para- graph. He says it is a "physical impossibility" that clock A should work more slowly than clock B and that the reciprocal should also be true. Let him measure time by the frequency of a laser, and suppose two identical lasers pointing at each other are in relative motion. he light received at each laser will be out of tune with the local standard and the phenomena observed at the two lasers will be identical. Knowing that the two lasers are identical, each observer can construct an algorithm so as to infer what time is being kept by the other and will rediscover the familiar and the relativistic Doppler correction. In other words, each frequency comparison will show that the distant laser is "running slow". Dingle's assertion that this is a physical impossibility is tantamount to the assertion that it is physically impossible for the velocity of light to be independent of its direction.

Dingle's confusion stems from his assertion that special relativity requires that the differences of rate should "actually and not merely apparently" occur. The truth, of course, is quite the opposite. The theory is cast in that positivist mould in which no meaning can be attached to physical quantities unless they are observed or made "apparent". It explicitly rejects the use of physical quantities which cannot be measured. By supposing that there can be measures of time more "actual" than those based on measurement, Dingle is simply asserting that he holds to the pre-relativity notion of absolute time.

Dingle likes to think of himself as the boy who first announced that the emperor had no clothes, but what he is really doing is to require that all innovations of physical theory should satisfy the test of commonsense. $\mathrm{He}$ cannot see that special relativity is important precisely because it modifies Newtonian commonsense. In the twelfth century, I suspect he would have resisted the notion that the Earth is round in similar terms, by issuing a challenge that the round earthers should either complete the sentence "the bottom hemisphere (from which people will be decanted into nothingness) is that which ..." or recant.

It may be asked why, if Dingle's question has such a simple answer, it has not been provided before the appearance of the leading article two and a half years ago. The explanation is that Dingle has shifted his ground. In 1968, he seemed to be seeking to demonstrate that special relativity is internally inconsistent. Now he appears to accept that the theory is consistent, but says that its consequences are unacceptable.

It is also fair to say that the issue, through no fault of Dingle's, has often been confused by debates about situations where the accurate definition of inertial frames is crucial but difficult.

In all the circumstances, if there is a moral obligation undischarged, it rests with Dingle. He should acknowledge his error, so inform his small, devoted and in my view misguided band of supporters and then finally make his peace with the relativists.

JOHN MADDOX

\section{London EC4}

\section{Scientific exchange}

SiR,-A brief note by Wendy Barnaby in your issue of May 8 reports on a new exchange agreement between "Swedish and Russian Academies of Science" and comments that the "agreement is unique in that, unlike the others the Russians have with western countries, it allows for the host country to invite specific scientists by name for study visits rather than accepting the other country's nominations." This principle is extremely important in the normalisation of scientific relations with the Soviets, and I should therefore like to point out that the National Academy of Sciences of the USA sought and obtained such an "invitational" provision in its exchange agreement with the Academy of Sciences of the USSR in 1968 applicable to one-month lecture visits by outstanding scientists and broadly applicable to all categories of exchange scientists, including those spending up to a year at research, in our Inter-Academy Exchange Agreement for 1974 and 1975.

Although this invitational approach seemed to be alien to the Soviet Academy's desires and practice with regard to a bilateral exchange agreement, the USSR Academy has increasingly acceded to the wishes of the National Academy of Sciences when it has requested consideration of the inclusion of individual named Soviet scientists whose presence is particularly desired at American universities.

LAWRENCE C. Mitchell

National Academy of Sciences,

Washington 20418

\section{From him and her}

SIR,-We think he doth edit with ghastful grammar: "A year's free subscription for he or she ... Ed." (May 8.) Egad!

EDWARD B. ARMSTRONG ElizaBeth B. ARMSTRONG;

Narrabri, NSW, Australia

Oh woe. Even Fowler, often a friend in need, allows me no escape from this rebuke save (a) that "it is hard not to sympathise with the victims of this trap", and (b) that Dickens did it, once. But the competition, in spite of all, is still open. En. 